\title{
Effect of Melting and Thermo-Diffusion on Natural Convection Heat Mass Transfer in a Non-Newtonian Fluid Saturated Non-Darcy Porous Medium
}

\author{
R.R. Kairi and P.V.S.N. Murthy* \\ Department of Mathematics, Indian Institute of Technology Kharagpur-721 302, India
}

\begin{abstract}
This paper investigates the influence of melting and thermo-diffusion effect on natural convection heat and mass transfer from vertical flat plate in a non-Newtonian fluid saturated non-Darcy porous medium. The wall and the ambient medium are maintained at constant but different levels of temperature and concentration such that the heat and mass transfer occurs from the wall to the medium. The Ostwald-de Waele power law model is used to characterize the non-Newtonian fluid behavior. A similarity solution for the transformed governing equations is obtained, computation is carried out for various values of the non-dimensional physical parameters. The variation in velocity, temperature, concentration, heat and mass transfer coefficients with the power law index, inertia parameter, melting parameter, thermodiffusion parameter, buoyancy ratio and Lewis number is discussed for a wide range of values of these parameters.
\end{abstract}

Keywords: Natural convection, thermo-diffusion, melting, non-Newtonian fluids, non-Darcy porous medium.

\section{INTRODUCTION}

The study of convective heat and mass transfer accompanied by melting effect in porous media has received a much attention in the recent years because of its important applications in casting, welding and magma solidification, permafrost melting and thawing of frozen ground etc. Epstein and Chao [1] studied the melting heat transfer from a flat plate in a steady laminar case, while Kazmierczak et al. $[2,3]$ analyzed melting from a vertical flat plate embedded in a porous medium in both free and forced convection processes. The heat transfer at the melting surface in the laminar boundary layer by using Karman-Pohlhausen method is discussed by Pozvonkov et al. [4]. Bakier [5] studied the melting effect on mixed convection from a vertical plate of arbitrary wall temperature both in aiding and opposing flows in a fluid saturated porous medium while Gorla et al. [6] considered similar study with uniform wall temperature conditions. Tashtoush [7] studied the magnetic and buoyancy effects to investigate the flow, temperature profiles and heat transfer characteristics for melting effect associated with uniform wall temperature based on nonDarcy flow model. The melting phenomena on unsteady and steady mixed convection heat transfer from a vertical plate in a liquid saturated porous medium with aiding and opposing external flows has been studied by Cheng and Lin [8,9]. Later they extended their work to the unsteady mass transfer $[10]$ by considering double diffusion processes.

Non-Newtonian power law fluids are so widespread in industrial processes and in the environment that it would be no exaggeration to affirm that Newtonian shear flows are the exception rather than the rule. Poulikakos and Spatz [11] analyzed the melting phenomena on free convection from a vertical front in a non-Newtonian fluid saturated porous

\footnotetext{
*Address correspondence to this author at the Department of Mathematics, Indian Institute of Technology Kharagpur-721 302, India;

E-mail:pvsnm@maths.iitkgp.ernet.in
}

matrix. Natural convection of a non-Newtonian fluid about a vertical wall and that around horizontal cylinder and sphere in a porous medium was presented by Chen and Chen [12] and Chen and Chen [13], respectively. Nakayama and Koyama [14] analyzed the more general case of free convection over a non-isothermal body of arbitrary shape embedded in a porous medium. Rastogi and Poulikakos [15] examined the problem of double diffusive convection from a vertical plate in a porous medium saturated with a nonNewtonian power law fluid. Shenoy [16] presented many interesting applications of non-Newtonian power law fluids with yield stress on convective heat transport in fluid saturated porous media considering geothermal and oil reservoir engineering applications. A unified similarity transformation for Darcy and non-Darcy forced, free and mixed convection heat transfer in non-Newtonian inelastic fluid-saturated porous media is studied by Nakayama and Shenoy [17]. Later, Shenoy [18] analyzed non-Darcy natural, forced and mixed convection heat transfer in non-Newtonian power-law fluid saturated porous media.

The diffusion of energy caused by a composition gradient is called the Dufour or diffusion-thermo effect. On the other hand, diffusion of mass due to temperature gradient is called Soret or thermo-diffusion effects. In liquid mixtures the Dufour terms is indeed very small and thus the Dufour effect will be negligible in comparison to the Soret effect. Hence one may ignore the Dufour terms when dealing with liquids. Alam and Rahman [19] studied the Dufour and Soret effects on steady MHD free convective heat and mass transfer flow past a semi-infinite vertical porous plate embedded in a porous media considering Soret Dufour effects. An analytical study of linear and non-linear double diffusive convection in couple stress liquids with Soret effect reported by Malashetty et al. [20]. Postelnicu [21] studied numerically the influence of chemical reaction on heat and mass transfer by natural convection from vertical surfaces in porous media considering Soret and Dufour effects. Thermal diffusion and MHD effects on combined, free-forced 
convection and mass transfer of a viscous fluid flow through a porous medium with heat generation is examined by Abdel-Rahman [22]. The linear stability analysis of Soretdriven thermo-solutal convection in a shallow horizontal layer of a porous medium subjected to inclined thermal and solutal gradients of finite magnitude is investigated theoretically by Narayana et al. [23].

The main purpose of the present investigation is to illustrate the effect of melting and thermal-diffusion on natural convection heat and mass transfer in a nonNewtonian fluid saturated non-Darcy porous medium, with a power law model for non-Newtonian fluid, using the similarity solution technique.

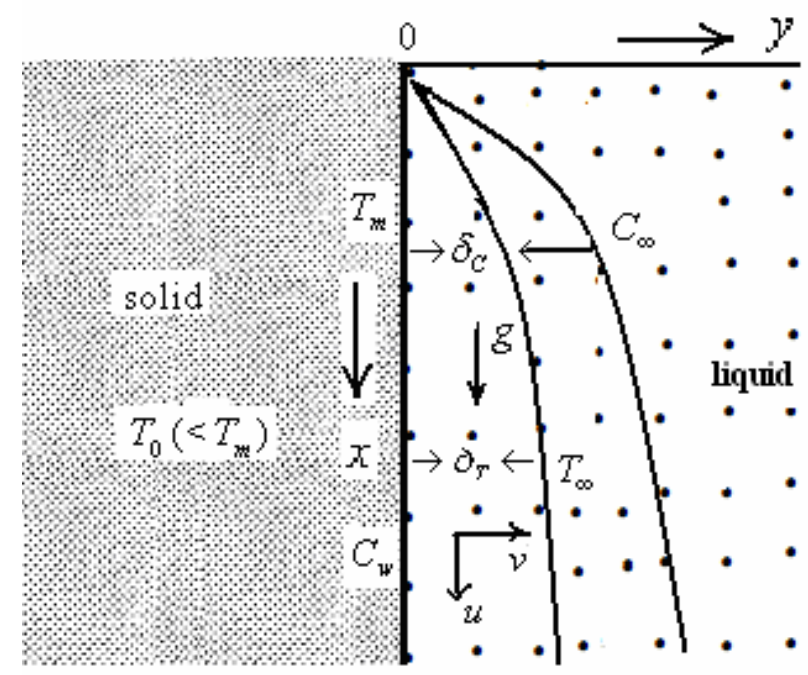

Fig. (1). Schematic of the interface (vertical line) separating the solid and liquid saturated porous medium.

\section{Mathematical Formulations}

Consider the free convection heat and mass transfer from a vertical plate embedded in a non-Darcy porous medium saturated with a non-Newtonian fluid. It is assumed that the plate constitutes the interface between the liquid phase and the solid phase during melting inside the porous matrix. The co-ordinate system and flow model are shown in the Fig. (1). The $x$-coordinate is taken along the plate, the $y$-coordinate is measured normal to the plate, while the origin of the reference system is taken at the leading edge of the plate. The fluid flow is moderate and the permeability of the medium is assumed to be low so that the Forchheimer flow model is applicable and the boundary-drag effect is neglected. The plate is at a constant temperature $T_{m}$ at which the material of the porous matrix melts. The liquid phase temperature is $T_{\infty}\left(>T_{m}\right)$ and the temperature of the solid far from the interface is $T_{0}\left(<T_{m}\right)$. The concentration at the wall is $C_{w}$ and the surrounding porous medium is maintained at constant concentration $C_{\infty}$. The flow is steady, laminar and two dimensional. With the usual boundary layer and linear Boussinesq approximations, the governing equations, namely the equation of continuity, the non-Darcy flow model (i.e. the model given by Shenoy [18]), the energy equation and the concentration equation for the isotropic and homogeneous porous medium may be written as

$$
\begin{aligned}
& \frac{\partial u}{\partial x}+\frac{\partial v}{\partial y}=0 \\
& \frac{\partial u^{n}}{\partial y}+\rho_{\infty} \frac{b k^{*}}{\mu^{*}} \frac{\partial u^{2}}{\partial y}=-\frac{\rho_{\infty} g k^{*}}{\mu^{*}}\left(\beta_{T} \frac{\partial T}{\partial y}+\beta_{C} \frac{\partial C}{\partial y}\right) \\
& u \frac{\partial T}{\partial x}+v \frac{\partial T}{\partial y}=\alpha \frac{\partial^{2} T}{\partial y^{2}} \\
& u \frac{\partial C}{\partial x}+v \frac{\partial C}{\partial y}=D \frac{\partial^{2} C}{\partial y^{2}}+D_{1} \frac{\partial^{2} T}{\partial y^{2}} .
\end{aligned}
$$

In the above equations, $u$ and $v$ are the Darcian velocity components along the $x$ and $y$ directions, $T$ and $C$ are the temperature and concentration, respectively, $n$ is the power law index. $\rho_{\infty}$ is the reference density, $g$ is the acceleration due to gravity, $\alpha=k /\left(\rho_{\infty} c_{f}\right)$ is the equivalent thermal diffusivity, $k$ is the effective thermal conductivity of the saturated porous medium, $D$ is the effective solutal diffusivities, respectively, $D_{1}$ quantifies the contribution to the mass flux due to temperature gradient, $\beta_{T}$ and $\beta_{C}$ are the thermal expansion coefficient and concentration expansion coefficient, respectively. Also, $b$ is the empirical constant associated with the Forchheimer porous inertia term and $\mu^{*}$ is the consistency index for power law fluid. Following Christopher and Middleman [24] and Dharmadhikari and Kale [25], the modified permeability of the flow $k^{*}$ of the non-Newtonian power law fluid is defined as

$$
k^{*}=\frac{1}{2 c_{t}}\left(\frac{n \varepsilon}{3 n+1}\right)^{n}\left(\frac{50 K}{3 \varepsilon}\right)^{\frac{n+1}{2}}
$$

where $K=\frac{\varepsilon^{3} d^{2}}{150(1-\varepsilon)^{2}}$ and

$$
c_{t}= \begin{cases}\frac{25}{12} & \text { Christopher and Middleman [24] } \\ \frac{2}{3}\left(\frac{8 n}{9 n+3}\right)^{n}\left(\frac{10 n-3}{6 n+1}\right)\left(\frac{75}{16}\right)^{3(10 n-3) /(10 n+1)} & \text { Dharmadhikariand Kale [25] }\end{cases}
$$

and for $n=1, c_{t}=\frac{25}{12}$.

The boundary conditions necessary to complete the problem formulation are written as:

$$
\begin{aligned}
& y=0: k \frac{\partial T}{\partial y}=\rho_{\infty}\left[L+c_{s}\left(T_{m}-T_{0}\right)\right] v, T=T_{m}, C=C_{w} \\
& y \rightarrow \infty: u \rightarrow 0, T \rightarrow T_{\infty}, C \rightarrow C_{\infty} .
\end{aligned}
$$

where $L$ and $c_{s}$ are latent heat of the solid and the specific heat capacity of the solid phase, respectively. 
The boundary condition (5) at the interface states that the temperature of the plate is equal to the melting temperature of the material saturating the porous matrix and the other condition means that the heat conducted to the melting surface is equal to the sum of heat of melting and the sensible heat required to raise the temperature of the solid, $T$ to its melting temperature $T_{m}$. It is important to note that the aforementioned equation is consistent with a coordinate system fixed to the melting surface, so that the interior of the solid appears to move towards the (stationary) melting surface with constant velocity equal to the melting velocity $\mathrm{v}(\mathrm{x}, 0)$. According to the present formulation, transient effects in the solid have been neglected. This assumption is valid as long as melting solid is large compared to its thermal boundary layer thickness [1].

The continuity equation is automatically satisfied by defining a stream function $\psi(x, y)$ such that $u=\frac{\partial \psi}{\partial y}$ and $v=-\frac{\partial \psi}{\partial x}$. We introduce the following similarity transformation:

$\eta=\frac{y}{x} R a_{x}^{1 / 2}, \quad \psi(\eta)=\alpha R a_{x}^{1 / 2} f(\eta), \quad \theta(\eta)=\frac{T-T_{m}}{T_{\infty}-T_{m}}$, $\phi(\eta)=\frac{C-C_{w}}{C_{\infty}-C_{w}}$

where $R a_{x}=\frac{x}{\alpha}\left[\frac{\rho_{\infty} k^{*} g \beta_{T}\left(T_{\infty}-T_{m}\right)}{\mu^{*}}\right]^{1 / n}$.

The above transformation reduces the system of partial differential equations into the following system of non-linear ordinary differential equations:

$\left(n f^{\prime^{n-1}}+2 G r^{*} f^{\prime}\right) f^{\prime \prime}=-\left(\theta^{\prime}+N \phi^{\prime}\right)$

$\theta^{\prime \prime}+\frac{1}{2} f \theta^{\prime}=0$

$\frac{1}{L e} \phi^{\prime \prime}+\frac{1}{2} f \phi^{\prime}+S_{r} \theta^{\prime \prime}=0$

The boundary conditions are

$\eta=0, f+2 M \theta^{\prime}=0, \theta=0, \phi=0$

$\eta \rightarrow \infty, f^{\prime} \rightarrow 0, \theta \rightarrow 1, \phi \rightarrow 1$.

In the above, $n$ is the power law index. The power law fluids with $n<1$ are called pseudoplastics, while those with $n>1$ are termed as dilatants. $M=\frac{c_{f}\left(T_{\infty}-T_{m}\right)}{L+c_{s}\left(T_{m}-T_{0}\right)}$ is the melting parameter, $S_{r}=\frac{D_{1}\left(T_{\infty}-T_{m}\right)}{\alpha\left(C_{w}-C_{\infty}\right)}$ is the Soret number,
$G r^{*}=b\left(\frac{k^{* 2} \rho_{\infty}^{2}\left[g \beta\left(T_{\infty}-T_{m}\right)\right]^{2-n}}{\mu^{*}}\right)^{1 / n}$ is the modified Grashof number. The buoyancy ratio is $N=\beta_{c} \phi_{w} / \beta_{T} \theta_{w}$ and $L e=\alpha / D$ is the Lewis number. The parameter $N>0$ represents the aiding buoyancy and $N<0$ represents the opposing buoyancy.

The non-dimensional heat and mass transfer coefficients are defined as

$$
\begin{aligned}
& N u_{x} / R a_{x}^{1 / 2}=\theta^{\prime}(0) \\
& S h_{x} / R a_{x}^{1 / 2}=\phi^{\prime}(0) .
\end{aligned}
$$

\section{RESULTS AND DISCUSSION}

The resulting ordinary differential equations (7)-(9) along with the boundary conditions (10)-(11) are solved using matlab BVP solver bvp4c which is a finite difference code that implements the 3-stage Lobatto IIIa formula. The integration length $\eta_{\infty}$ varies with the parameter values and it has been suitably chosen each time such that the boundary conditions at the outer edge of the boundary layer are satisfied. The results obtained here are accurate up to the $4^{\text {th }}$ decimal place. In order to assess the accuracy of the solution, the present results for the Nusselt number are compared with those obtained by Poulikakos and Spatz [11] with $N=0$ and $S_{r}=0$, the trend shows that the results are in good agreement. The following values are considered for the parameters: $\quad 0.5 \leq n \leq 1.5, \quad 0 \leq M \leq 1, \quad-0.5 \leq N \leq 3$, $-0.5 \leq S_{r} \leq 0.5, \quad 0.5 \leq L e \leq 5$ and $0.01 \leq G r^{*} \leq 0.1$. The variation of heat and mass transfer coefficients are shown for some selected values of the parameters through figures.

\section{Aiding Buoyancy}

Figs. (2-4) show the non-dimensional velocity $f^{\prime}$, temperature $\theta$ and concentration $\phi$ profiles for various values of power law index $n$ and melting parameter $M$ for fixed values of $N, G r^{*}, L e$ and $S_{r}$. It can be seen from Fig. (2) that the values of the slip velocity, $f^{\prime}(0)$, decreases as the power law index $n$ increases. As the power law index $n$ increases, the momentum, temperature and concentration boundary layer thicknesses increases. Increasing the melting parameter $M$ increases the velocity inside the boundary layer and, therefore, it decreases the temperature and concentration distributions.

The variation of Nusselt and Sherwood number versus the power law index parameter $n$ for different values of $M$ and $S_{r}$ is shown in Figs. $(\mathbf{5}, \mathbf{6})$. As the power law index $n$ and the melting parameter $M$ increases, the Nusselt and Sherwood number decreases. The reason for this is that increasing the power law index $n$ and the melting parameter $M$ increases thermal and concentration boundary layer thickness (see Figs. 3, 4) which results in a reduction in 


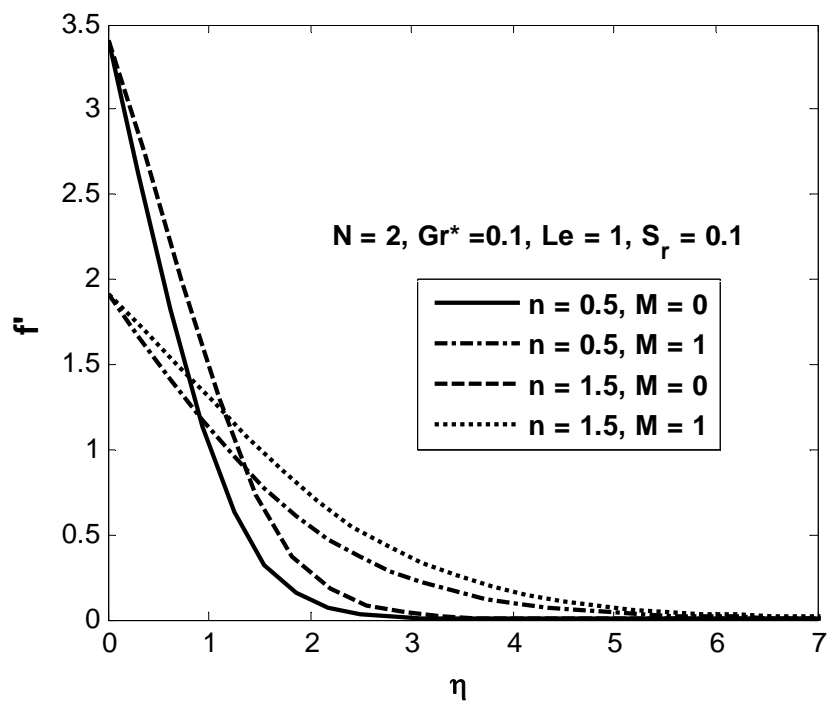

Fig. (2). Variation of velocity profiles with similarity variable $\eta$ for aiding buoyancy $(N>0)$.

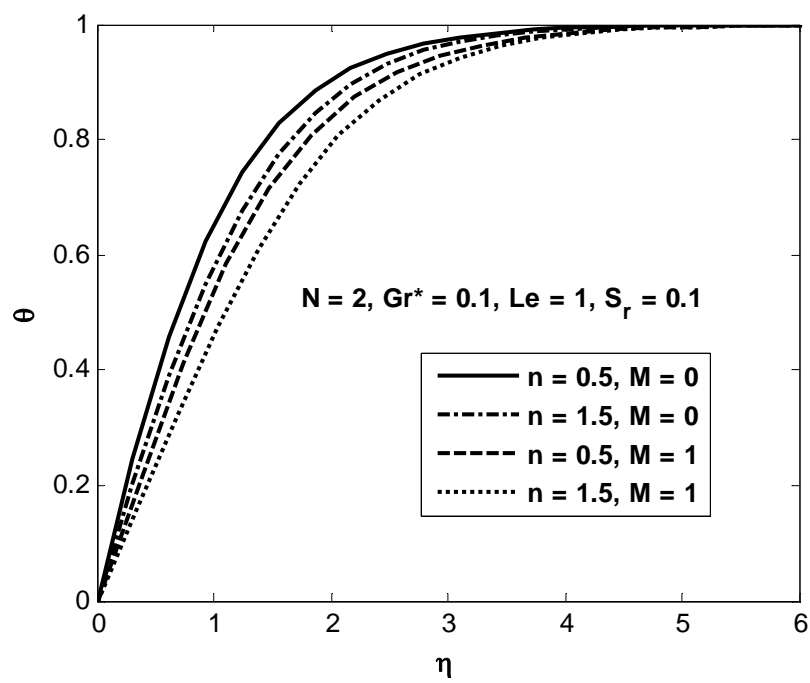

Fig. (3). Variation of temperature profiles with similarity variable $\eta$ for aiding buoyancy $(N>0)$.

temperature and concentration gradient at the surface of the plate. Also it can be noted that as the Soret parameter $S_{r}$ increases the heat transfer coefficient increases but the mass transfer coefficient reduces for all values of $n$. This is because, either a decrease in concentration difference or an increases in temperature difference leads to an increase in the value of the Soret parameter $S_{r}$. Hence increasing the parameter $S_{r}$ increases the non-dimensional heat transfer coefficient and decreases the mass transfer coefficient. The effect of Soret parameter on the heat and mass transfer coefficient reduces with increasing $M$ for all values of $n$.

Fig. (7) depicts the effect of Le on the heat transfer coefficient for varying $n$ and $M$. It is clearly seen from this figure that as $L e$ increases the reduction due to increasing $M$ in heat transfer coefficient reduces for both pseudoplastic and dilatant fluids. Also, it is more for the dilatants in the whole range of $L e$. The variation of mass transfer coefficient against $L e$ for different values of $n$ and $M$ is illustrated in the Fig. (8). It is observed that as $L e$ increases the reduction in the mass transfer coefficient due to increase in the value of the melting parameter $M$ increases. It is also noticed that this reduction is more for dilatants when compared to pseudoplastic fluids.

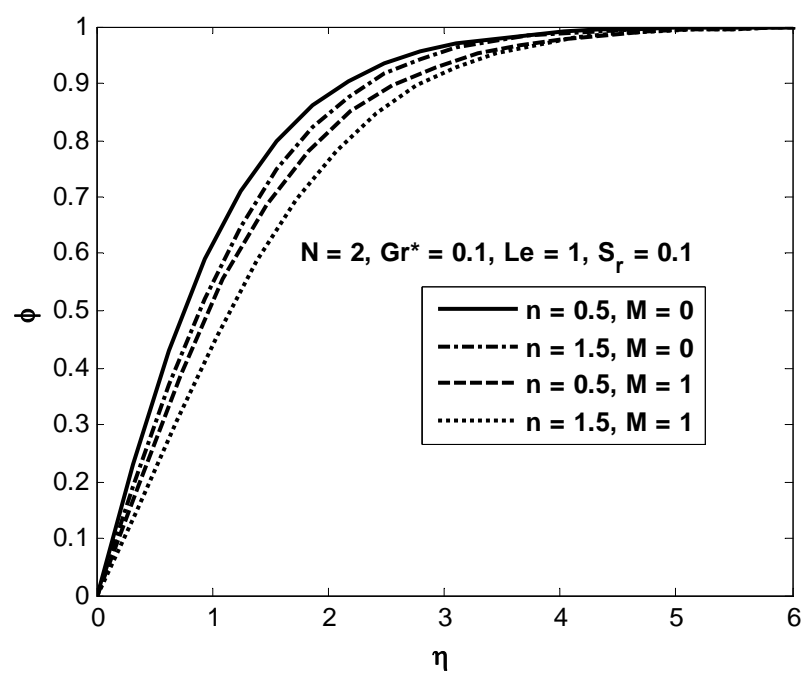

Fig. (4). Variation of concentration profiles with similarity variable $\eta$ for aiding buoyancy $(N>0)$.

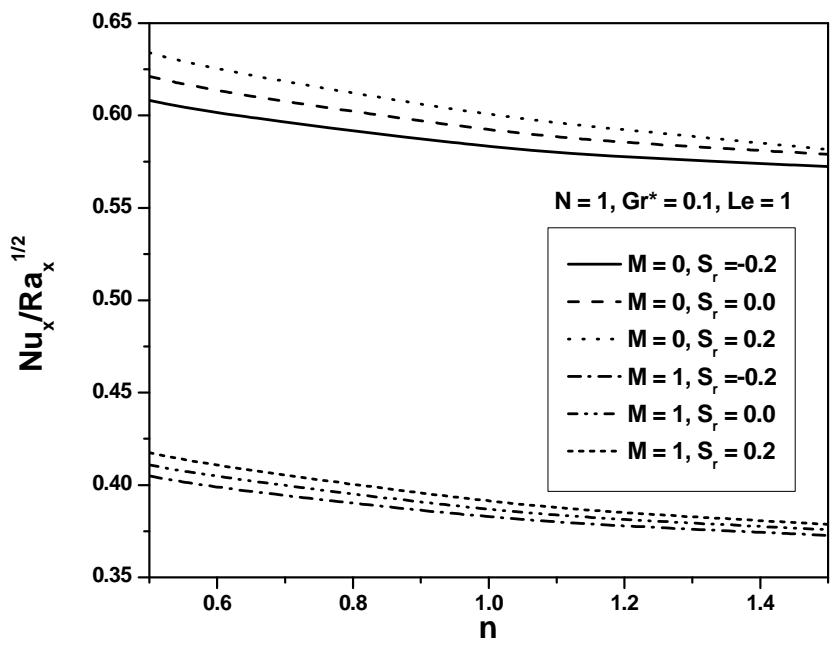

Fig. (5). Variation of heat transfer coefficient against $n$ for varying $M$ and $S_{r}$.

\section{Opposing Buoyancy}

The variation of non-dimensional velocity $f^{\prime}$, temperature $\theta$ and concentration $\phi$ against the similarity variable $\eta$ for different values of $n$ and $M$ is shown in Figs. (9-11). It is observed from these figures that slip velocity, $f^{\prime}(0)$, increases with $n$ and the momentum, temperature and concentration boundary layer thickness decreases with $n$, therefore, heat and mass transfer rate increases with the power law index $n$. With the increase in the value of the melting parameter $M$, an identical behavior is observed, as in 
case of aiding buoyancy, on the velocity, temperature and concentration fields.

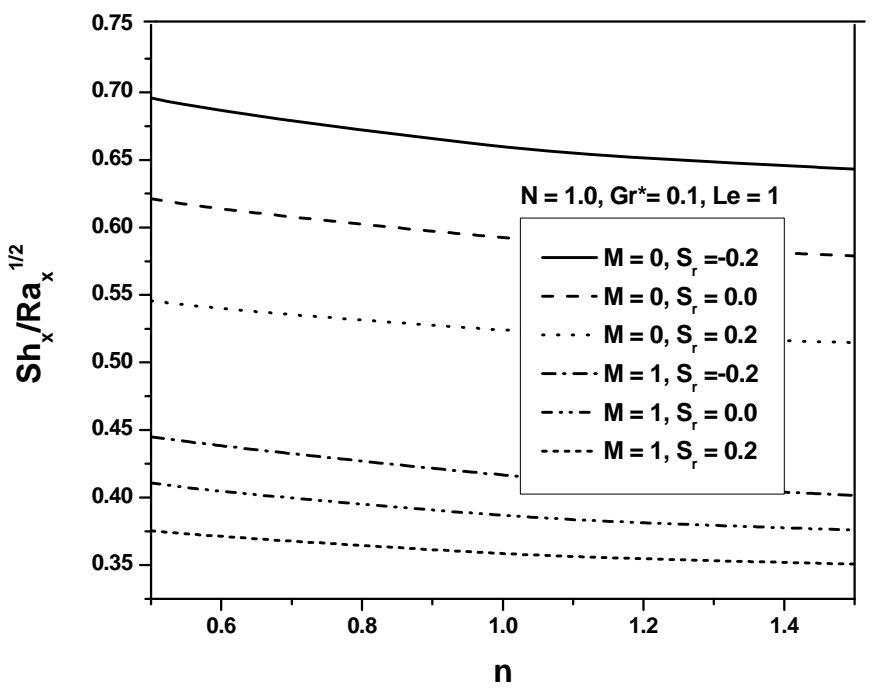

Fig. (6). Variation of mass transfer coefficient against $n$ for varying $M$ and $S_{r}$.

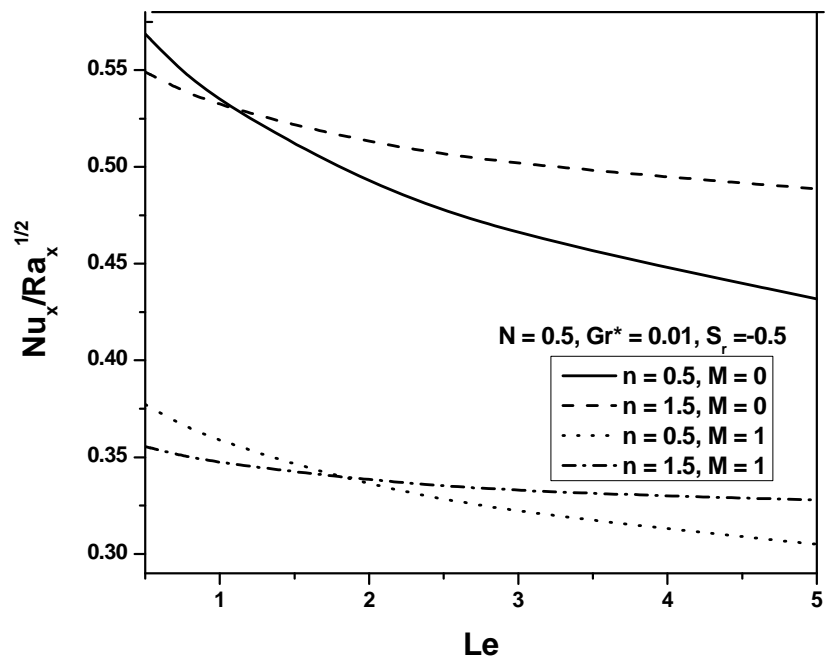

Fig. (7). Variation of heat transfer coefficient against $L e$ for varying $n$ and $M$.

The variations of the Nusselt and Sherwood number as a function of power law index $n$ is shown for three different values of $M$ and $S_{r}$ in Figs. $(12,13)$ respectively with fixed values of the other parameters. From these figures it is evident that increasing the melting parameter $M$ reduces the heat and mass transfer coefficient. Also it plays a vital role in reducing the heat and mass transfer coefficient for dilatants in the medium compared with that for pseudoplastics. It can be noted from these figures that increase in $S_{r}$ reduces the heat and mass transfer coefficient for all values of the power law index $n$. The effect of $S_{r}$ on the heat and mass transfer coefficient reduces as the melting parameter increases.

Figs. $(\mathbf{1 4}, \mathbf{1 5})$ illustrate the variation of the Nusselt and Sherwood numbers against $L e$ for different values of $n$ and $M$, respectively with fixed value of other parameters. It is observed that as $L e$ increases the reduction due to increment in the melting parameter on the Nusselt and Sherwood number increases. Also it can be noted that the reduction is more pronounced for dilatant fluids in the porous medium.

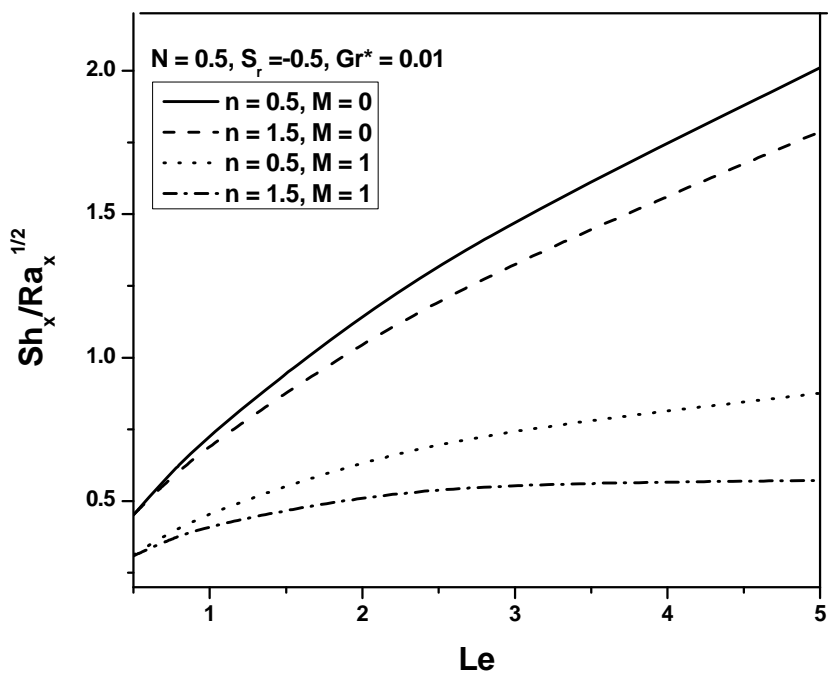

Fig. (8). Variation of mass transfer coefficient against Le for varying $n$ and $M$.

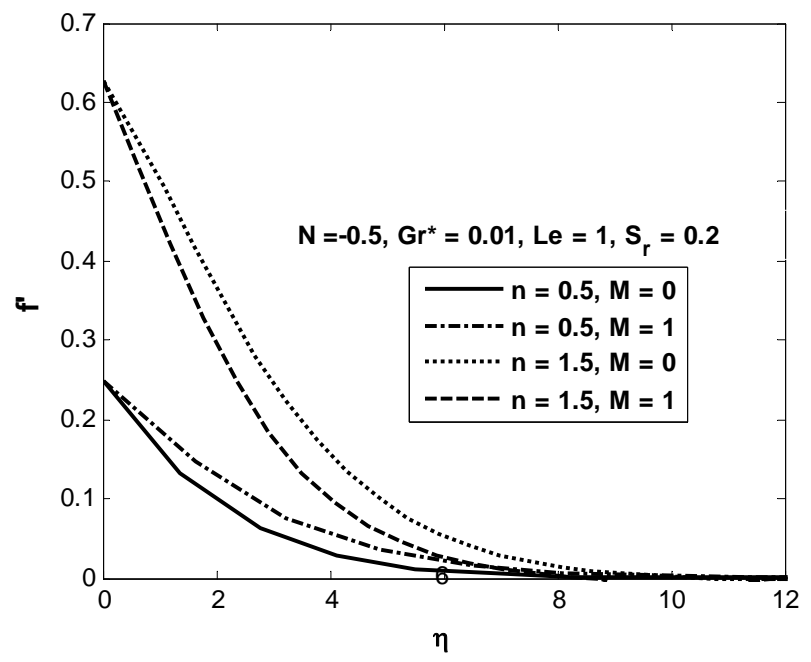

Fig. (9). Variation of velocity profiles with similarity variable $\eta$ for opposing buoyancy $(N<0)$.

\section{CONCLUSIONS}

In this study the melting phenomena with thermodiffusion effect on free convection from a vertical flat plate with constant wall temperature and concentration embedded in a non-Darcy porous medium saturated with nonNewtonian fluid is analyzed. Both the aiding and opposing buoyancies are considered for analysis, and the heat and mass transfer coefficients are obtained for various values of flow influencing parameters. The results are analyzed thoroughly for different cases of $L e<1, L e=1$, and $L e>1$. It is noted that the velocity, temperature and concentration profiles as well as the heat and mass transfer coefficients are significantly affected by the melting phenomena and thermal-diffusion in the medium. The major conclusion is 


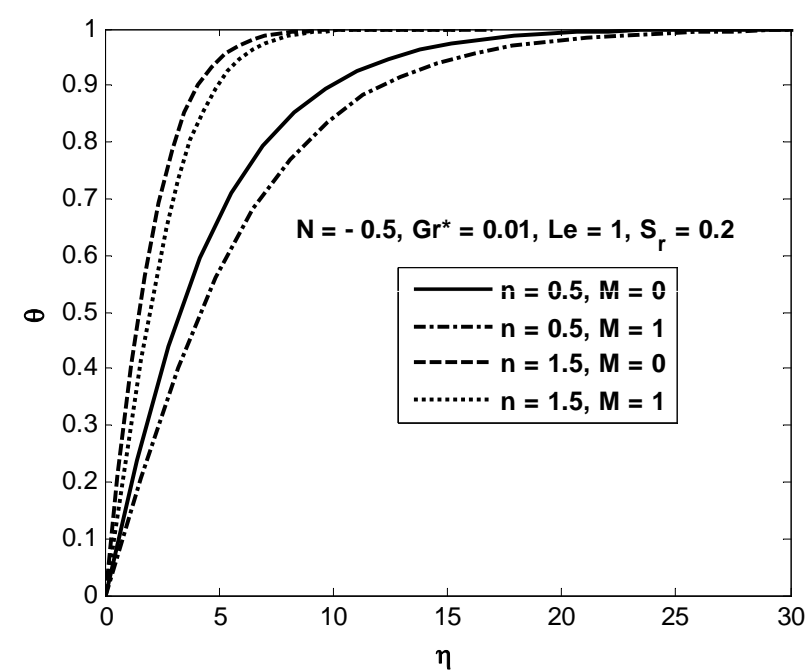

Fig. (10). Variation of temperature profiles with similarity variable $\eta$ for opposing buoyancy $(N<0)$.

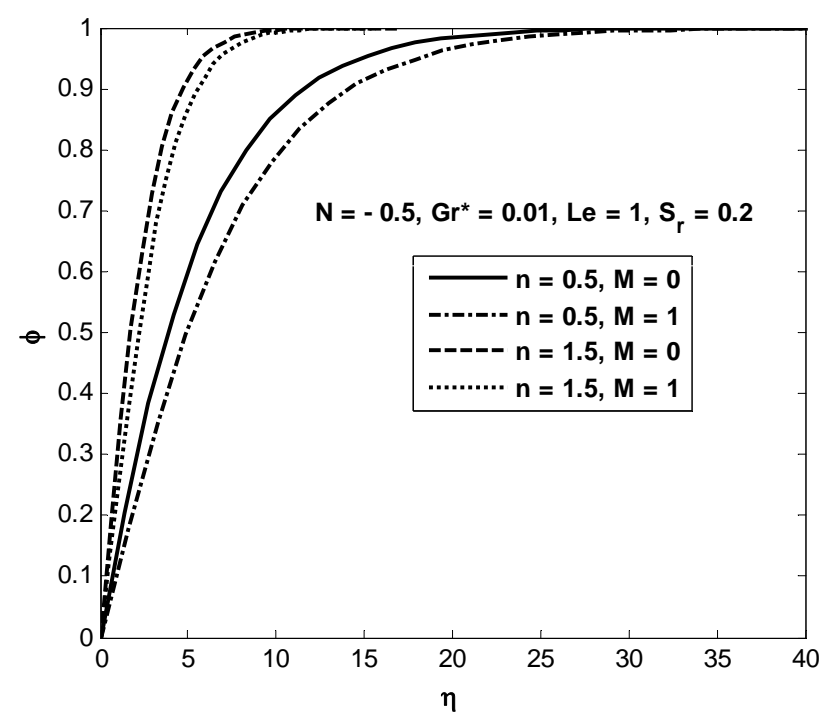

Fig. (11). Variation of concentration pr iles with similarity variable $\eta$ for opposing buoyancy $(N<0)$.

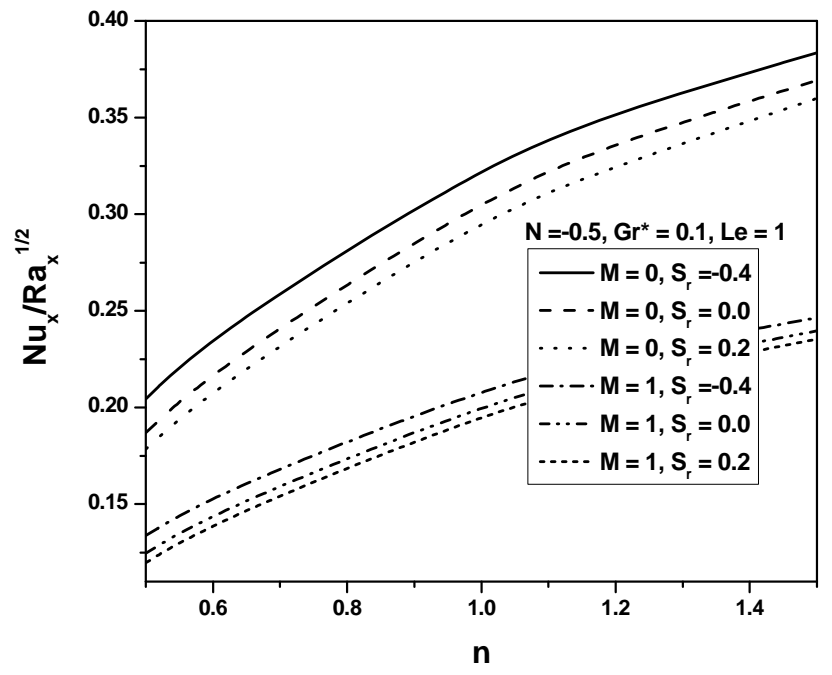

Fig. (12). Variation of heat transfer coefficient against $n$ for varying $M$ and $S_{r}$.

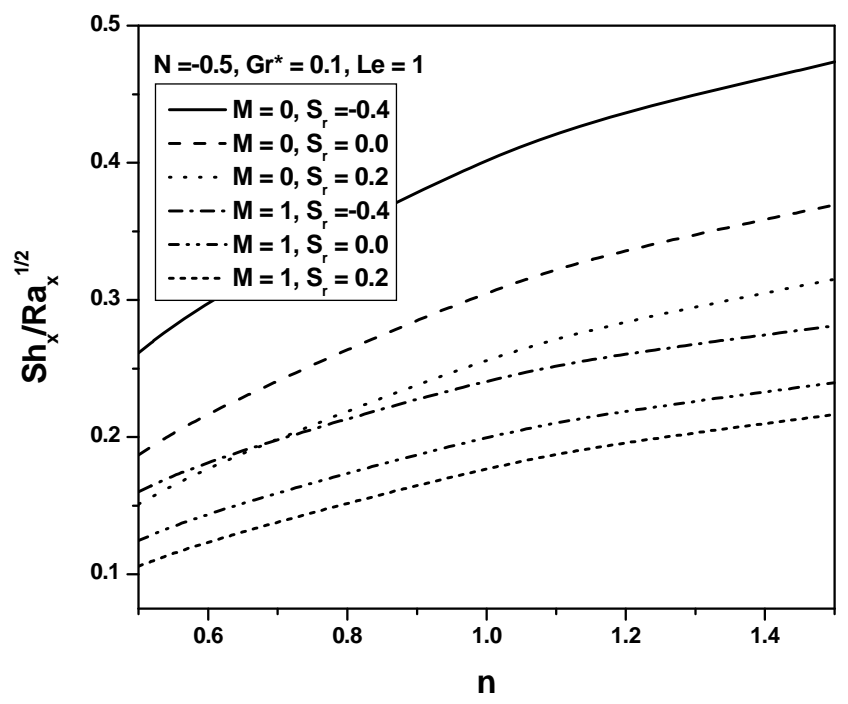

Fig. (13). Variation of mass transfer coefficient against $n$ for varying $M$ and $S_{r}$.

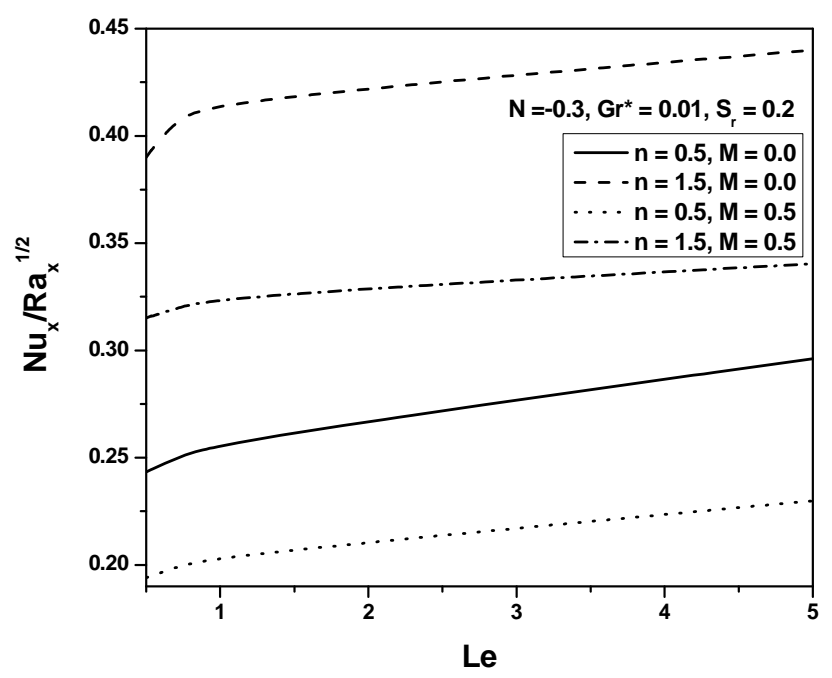

Fig. (14). Variation of heat transfer coefficient against Le for varying $n$ and $M$.

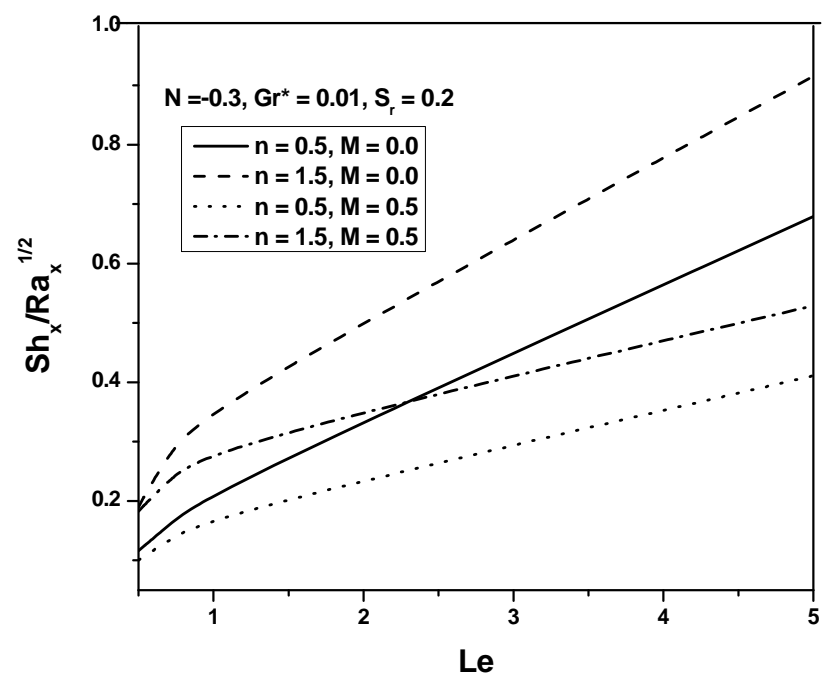

Fig. (15). Variation of mass transfer coefficient against Le for varying $n$ and $M$. 
that the heat and mass transfer coefficient are reduces with increasing value of the melting parameter $M$ for all $n(>,=,<1)$. The effect of Soret parameter on the heat and mass transfer coefficient reduces with increasing value of the melting parameter in the whole range of $n$. Finally, the effect melting on the heat and mass transfer coefficient is more significant for dilatant fluids in the medium, compared to pseudoplastics.

\section{NOMENCLATURE}

$$
\begin{aligned}
& b \quad=\text { Coefficient in the Forchheimer term } \\
& c_{f}=\text { Specific heat capacity of the convective fluid } \\
& {[\mathrm{J} / \mathrm{kg} \mathrm{K}]} \\
& c_{s}=\text { Specific heat capacity of the solid phase }[\mathrm{J} / \mathrm{kg} \mathrm{K}] \\
& d \quad=\text { Pore diameter }[\mathrm{m}] \\
& D \quad=\text { Solutal diffusivity }\left[\mathrm{m}^{2} / \mathrm{s}\right] \\
& D_{1} \quad=\text { Soret coefficient } \\
& \varepsilon=\text { Porosity of the saturated porous medium } \\
& f \quad=\text { Dimensionless stream function } \\
& g=\text { Acceleration due to gravity }\left[\mathrm{m} / \mathrm{s}^{2}\right] \\
& k^{*}=\text { Intrinsic permeability of the porous medium for } \\
& \text { flow of power law fluid }\left[\mathrm{m}^{2}\right] \\
& K=\text { Permeability of the porous medium }\left[\mathrm{m}^{2}\right] \\
& G r^{*}=\text { Non-Darcian (inertia) parameter or Grashof } \\
& n \quad=\text { Power law index } \\
& N \quad=\text { Buoyancy ratio } \\
& \mathrm{Nu}=\text { Nusselt number } \\
& \text { Sh }=\text { Sherwood number } \\
& S_{r} \quad=\text { Thermal-diffusion or Soret parameter } \\
& L=\text { Latent heat of the solid }[\mathrm{J} / \mathrm{kg}] \\
& \text { Le } \quad=\text { Lewis number } \\
& T \quad=\text { Temperature }[\mathrm{K}] \\
& C=\text { Concentration } \\
& x, y=\text { Axial and normal co-ordinates [m] } \\
& u, v=\text { Velocity components in } \mathrm{x} \text { and } \mathrm{y} \text { directions }[\mathrm{m} / \mathrm{s}]
\end{aligned}
$$

\section{Greek Symbols}

$\mu^{*}=$ Fluid consistency of the inelastic non-Newtonian power-law fluid $[\mathrm{kg} /(\mathrm{ms})]$

$\rho_{\infty}=$ Reference density at some point $\left[\mathrm{kg} / \mathrm{m}^{3}\right]$

$\alpha=$ Thermal diffusivity $\left[\mathrm{m}^{2} / \mathrm{s}\right]$

$\beta_{T}=$ Coefficient of thermal expansion $[1 / \mathrm{K}]$ $\beta_{c}=$ Coefficient of solutal expansion $[1 / \mathrm{K}]$

$\psi \quad=$ Dimensionless stream function

$\eta \quad=$ Similarity variable

$\theta=$ Dimensionless temperature

$\varphi \quad=$ Dimensionless concentration

$\theta_{w} \quad=T_{\infty}-T_{m}$

$\varphi_{w} \quad=C_{w}-C_{\infty}$

\section{Subscripts}

$w, \infty=$ Conditions on the wall and at the ambient medium

\section{ACKNOWLEDGEMENTS}

The authors are thankful to the reviewers for their constructive criticism which helped us in improving this article. Both the authors would like to acknowledge sincerely the financial assistance received from the CSIR, India through the research project grant numbers respectively, 09/081(0596)/2006-EMR-1 and 25(155)/07/EMR-II.

\section{REFERENCES}

[1] M. Epstein, and D. H. Cho, "Melting heat transfer in steady laminar flow over a flat plate", ASME Journal of Heat Transfer, vol. 98, pp. 531-533, 1976.

[2] M. Kazmierczak, D. Poulikakos, and I. Pop, "Melting from a flat plate embedded in a porous medium in the presence of steady convection", Numerical Heat Transfer, vol. 10, pp. 571-581, 1986.

[3] M. Kazmierczak, D. Poulikakos, and D. Sadowski, "Melting of a vertical plate in porous medium controlled by forced convection of a dissimilar fluid", International Communication in Heat Mass Transfer, vol. 14, pp. 507-517, 1987.

[4] F. M. Pozvonkov, E. F. Shurgalskii, and L. S. Akselrod, "Heat transfer at a melting flat surface under conditions of forced convection and laminar boundary layer", International Journal of Heat and Mass Transfer, vol. 13, pp. 957-962, 1970.

[5] A. Y. Bakier, "Aiding and opposing mixed convection flow in melting from a vertical flat plate embedded in a porous medium", Transport in Porous Media, vol. 29, pp. 127-139, 1997.

[6] R. S. R. Gorla, M. A. Mansour, I. A. Hassanien, and A. Y. Bakier, "Mixed convection effect on melting from a vertical plate in a porous medium", Transport in Porous Media, vol. 36, pp. 245-254, 1999.

[7] B. Tashtoush, "Magnetic and buoyancy effects on melting from a vertical plate embedded in a saturated porous media", Energy Conversion and Management, vol. 46, pp. 2566-2577, 2005.

[8] W. T. Cheng, and C. H. Lin, "Transient mixed convective heat transfer with melting effect from the vertical plate in a liquid saturated porous medium", International Journal of Engineering Science, vol. 44, pp. 1023- 1036, 2006.

[9] W. T. Cheng, and C. H. Lin, "Melting effect on mixed convective heat transfer with aiding, and opposing external flows from the vertical plate in a liquid-saturated porous medium", International Journal of Heat and Mass Transfer, vol. 50, pp. 3026-3034, 2007.

[10] W. T. Cheng, and C. H. Lin, "Unsteady mass transfer in mixed convective heat flow from a vertical plate embedded in a liquid saturated porous medium with melting effect", International Communication in Heat Mass Transfer, vol. 35, pp. 1350-1354, 2008.

[11] D. Poulikakos, and T. L. Spatz, "Non-Newtonian natural convection at a melting front in a permeable solid matrix", International Communication in Heat Mass Transfer, vol. 15, pp. 593-603, 1988

[12] H. T. Chen, and C. K. Chen, "Natural convection of nonNewtonian fluids along a vertical plate embedded in a porous medium", ASME Journal of Heat Transfer, vol. 110, pp. 257-260, 1988. 
[13] H. T. Chen, and C. K. Chen, "Natural convection of a nonNewtonian fluid about a horizontal cylinder and sphere in a porous medium", International Communications in Heat and Mass Transfer, vol.15, pp. 605-614, 1988.

[14] A. Nakayama, and H. Koyama, "Buoyancy induced flow of nonNewtonian fluids over a non-isothermal body of arbitrary shape in a fluid-saturated porous medium", Applied Scientific Research, vol. 48, pp. 55-70, 1991.

[15] S. K. Rastogi, and D. Poulikakos, "Double-diffusion from a vertical surface in a porous region saturated with a nonNewtonian fluid", International Journal of Heat and Mass Transfer, vol. 38, pp. 935-946,1995.

[16] A. V. Shenoy, "Non-Newtonian fluid heat transfer in porous media", Advances in Heat Transfer vol. 24, New York: Academic Press, 1994, pp. 101-190.

[17] A. Nakayama, and A. V. Shenoy, "A unified similarity transformation for Darcy and non-Darcy forced, free and mixed convection heat transfer in non-Newtonian inelastic fluid-saturated porous media", The Chemical Engineering Journal, vol. 50, pp. 33$45,1992$.

[18] A. V. Shenoy, "Darcy-Forchheimer natural forced and mixed convection heat transfer in non-Newtonian power-law fluidsaturated porous media", Transport in Porous Media, vol. 11, pp. 219-241, 1993.

[19] M. S. Alam, and M. M. Rahman, "Dufour and Soret effects on MHD free convection heat and mass transfer flow past a vertical flat plate embedded in a porous medium", Journal of Naval Architecture and Marine Engineering, vol. 2, pp. 55-65, 2005.

[20] M. S. Malashetty, S. N. Gaikwad, and M. Swamy, "An analytical study of linear and non-linear double diffusive convection with Soret effect in couple stress liquids", International journal of thermal science, vol. 45, pp. 897-907, 2006.

[21] A. Postelnicu, "The influence of chemical reaction on heat and mass transfer by natural convection from vertical surfaces in porous media considering Soret Dufour effects", Heat Mass Transfer, vol. 43, pp. 595-602, 2007.

[22] G. M. Abdel-Rahman, "Thermal diffusion and MHD effects on combined, free-forced convection and mass transfer of a viscous fluid flow through a porous medium with heat generation", Chemical Engineering Technology, vol. 31, pp. 554-559, 2008.

[23] P. A. L. Narayana, P. V. S. N. Murthy, and R. S. R. Gorla, "Soretdriven thermo-solutal convection induced by inclined thermal and solutal gradients in a shallow horizontal layer of a porous medium", Journal of Fluid Mechanics, vol. 612, pp. 1-19, 2008.

[24] R. H. Christopher, and S. Middleman, "Power law fluid flow through a packed tube", Indusrial and Engineering Chemistry Fundamentals, vol. 4, pp. 422-426, 1965.

[25] R. V. Dharmadhikari, and D. D. Kale, "The flow of non-Newtonian fluids through porous media", Chemical Engineering Science, vol. 40, pp. 527-529, 1985. 